\title{
Evaluation of Risk Factors and Follow-Up Criteria for Severity of Snakebite in Children
}

\author{
Fesih Aktar,, ${ }^{1,}$ Safak Aktar, ${ }^{2}$ Ilyas Yolbas, ${ }^{3}$ and Recep Tekin ${ }^{4}$ \\ ${ }^{1}$ Pediatric Infectious Disease Department, School of Medicine, Dicle University, Diyarbakir, Turkey \\ ${ }^{2}$ Plastic Surgery, Van Research and Education Hospital, Van, Turkey \\ ${ }^{3}$ Pediatrics Department, Dicle University School of Medicine, Diyarbakir, Turkey \\ ${ }^{4}$ Clinical Microbiology and Infectious Disease Department, School of Medicine, Dicle University, Diyarbakir, Turkey \\ "Corresponding author: Fesih Aktar, Pediatric Infectious Disease Department, School of Medicine, Dicle University, Diyarbakir, Turkey. Tel: +90-5056690064, Fax: \\ +90-412.248-8523, E-mail: fesihaktar@yahoo.com
}

Received 2015 December 30; Revised 2016 April 20; Accepted 2016 May 28.

\begin{abstract}
Background: Snakebites are an emergency medical condition and require rapid treatment procedures in children.

Objectives: This study aimed to present an overview of the demographic characteristics, clinical presentations, laboratory findings, severity, and complications that developed in pediatric patients due to snakebites.

Patients and Methods: A total of 151 children with snakebite were enrolled in the study. All patients had a history of snakebite obtained between June 2006 and August 2015 retrospectively.

Results: Duration of hospitalization $(\mathrm{P}<0.001)$, rural occurrence $(\mathrm{P}<0.001)$, white blood cell (WBC) count $(\mathrm{P}=0.002)$, aspartate aminotransferase to alanine aminotransferase (AST/ALT) ratio $(\mathrm{P}=0.010)$, hypoproteinemia $(\mathrm{P}=0.001)$, hypoalbuminemia $(\mathrm{P}$ $<0.001)$, and hypocalcemia $(\mathrm{P}=0.005)$ were significantly high in the severe snakebite group. WBC $(\mathrm{P}=0.006)$ and AST/ALT ratio $(\mathrm{P}$ $=0.018$ ) were significantly higher on the first day of the snakebite than on subsequent days.

Conclusions: Children admitted to the hospital due to snakebite should be monitored for at least 24 - 48 hours even if no signs of clinical envenomation could be observed. According to the severity of the disease, antivenom should be administered to the patients. Duration of hospitalization, rural occurrence, WBC count, AST/ALT ratio, CK, hypoproteinemia, hypoalbuminemia, and hypocalcemia can be associated with the severity of snakebite. WBC AST/ALT ratio can be used as follow-up criteria in children with snakebite
\end{abstract}

Keywords: Snakebite, Envenomation, Antivenom, Child

\section{Background}

Snakebite is a serious condition requiring rapid treatment procedures. Among the 3,500 known snake species, less than $10 \%$ are poisonous. Venomous snakebites in children are uncommon but have the potential for significant morbidity and occasional mortality. About 3,000,000 snakebite cases and 150,000 deaths due to snakebites are recorded annually worldwide (1-3). Mortality due to snakebite nearly reached $25 \%$ in previous years, but it decreased to below $0.5 \%$ through the easy access to antivenom and the development of emergency interventions (1). In Turkey, snakebite cases are common especially in the Southeastern Anatolia region because of its climatic and geographical characteristics. The most common kind of snake in this region is Viperidae lebetina (3). Viperidae venom has necrotizing and hemorrhagic effects (3). The clinical course of snakebite is more severe and more complicated in children than in adults. No studies on snakebites have been conducted among the pediatric pop- ulation in Turkey.

\section{Objectives}

This study aimed to investigate the demographic characteristics, severity of snakebite, laboratory findings, complications, and risk factors of prolonged hospitalization and clinical severity of snakebite in children.

\section{Patients and Methods}

This retrospective study was performed by Dicle University department of pediatrics. Our hospital is a referral hospital in Southeast Anatolia in Turkey. The information of all patients with a history of snakebite between June 2006 and August 2015 was obtained from hospital records.

A total of 151 children with snakebite were enrolled in the study. The condition of snakebite patients admitted to the hospital was monitored from the time of admission to 
the end of their hospital stay. The included cases were further confirmed on the basis of the clinical symptoms of local swelling and hemotoxicity.

Patient data were obtained from the patient follow-up forms completed at admission and from hospital records. Age, gender, location of bite, duration of hospitalization (days), severity of envenomation, symptoms and clinical findings, electrocardiogram for $\mathrm{T}$ wave crash, laboratory data, specific treatment approaches (dose of snake toxin antiserum, plaster and splint, and antibiotics), complications, and outcomes were evaluated.

Laboratory data included hemogram parameters such as first, fifth, and tenth day of white blood cell (WBC) count; hemoglobin ( $\mathrm{Hb})$; platelet count; and biochemical parameters such as urea, creatinine, calcium, aspartate aminotransferase (AST), alanine aminotransferase (ALT), total protein, albumin, creatine kinase (CK), and prothrombin time at admission were recorded.

Demographic features, hemogram, and biochemical parameters were compared according to the severity of envenomation in the study group. Mild envenomation is defined as swelling involving one or two segments of the bitten limb and less than a $4 \mathrm{~cm}$ increase in limb circumference with no bleeding at the bite site, as well as no necrosis or systemic symptoms. Moderate envenomation is defined as swelling involving two or three segments of the bitten limb and more than $4 \mathrm{~cm}$ increase in limb circumference with local bleeding at the bite site, no local necrosis, and minimal or no systemic symptoms. Severe envenomation results in swelling extending beyond the bitten limb (to the trunk), blisters, local bleeding, necrosis or compartment syndrome, and clinical systemic signs (multiple systemic bleeding, hypotension or shock, disseminated intravascular coagulation or renal failure, cerebral hemorrhage, or multi-systemic failure) (4).

Patients who did not have bite marks of a snake and any other forms of unknown bites that were not snakebites, were over 18 years old, and whose file records were inaccessible were excluded from the study.

The study protocol was approved by the noninterventional clinical research ethics committee of Dicle University medical faculty.

\subsection{Statistical Analysis}

The data were analyzed using the statistical package for social sciences version 18.0 program for Windows. The Kolmogorov-Smirnov test was used to determine whether or not the numerical variables exhibited normal distribution. Variables with normal distribution were expressed as mean \pm standard deviation, whereas variables without normal distribution were expressed as median (minimum-maximum) values. Independent groups were com- pared using Student's t-test. Categorical variables were analyzed using the chi-square test. Friedman's test was used to compare the distributions of two or more quantitative variables. Cumulative incidence was calculated for the entire duration of the study with $95 \%$ confidence intervals. $P$ values $<0.05$ (two-sided, where applicable) were considered statistically significant.

\section{Results}

A total of 151 children with snakebite were enrolled in the study. Among them, 99 (65.6\%) were male and the average age was $119.6 \pm 37.8$ months. The most frequent area of occurrence was the rural area at $65.6 \%(n=99)$. The most common location of the bites was the right forearm at $61.6 \%(n=93)$. Among the patients, $32(21.2 \%)$ had mild, 73 (48.3\%) had moderate, and 46 (30.5\%) had severe snakebites. The median duration of hospitalization was 6 (1 - 26) days. The most common findings from the physical examination of the patients were edema, ecchymosis, necrosis, and tachycardia. The most common complication was compartment syndrome at a rate of $28.5 \%$ ( $\mathrm{n}=$ 43), and all patients were discharged without any complications. The median administered snake antivenom was 1 (1 - 5) dose. A plaster splint was applied to 48 (31.8\%) patients, and 145 (96.0\%) patients received prophylactic treatment with antibiotics. No fatalities were reported in the study. An overview of demographic features, clinical features on admission, treatment, and outcomes of the patients is summarized in Table 1.

Duration of hospitalization ( $\mathrm{P}<0.001)$, rural occurrence $(\mathrm{P}<0.001), \mathrm{WBC}(\mathrm{P}=0.002), \mathrm{AST} / \mathrm{ALT}$ ratio $(\mathrm{P}=0.010)$, CK $(\mathrm{P}<0.001)$, hypoproteinemia $(\mathrm{P}=0.001)$, hypoalbuminemia $(\mathrm{P}<0.001)$, and hypocalcemia $(\mathrm{P}=0.005)$ were significantly high in the severe snakebite group (Table 2 ). No statistically significant differences were found among the severity group in terms of age, gender, hemoglobin, platelet count, urea, creatine, and prothrombin time values $(\mathrm{P}>0.05)$ (Table 2$)$.

WBC $(P=0.006)$ and AST/ALT ratio $(P=0.018)$ were significantly higher on the first day of the snakebite than on subsequent days (Table 3 ).

\section{Discussion}

Snake venom has many effects, and the most common of which is hematotoxicity. Patients can develop local or systemic symptoms depending on the severity of the venom toxin (5-7). Pain, increased temperature, edema, ecchymosis, hemorrhage, tissue necrosis, and systemic findings such as fever, nausea, vomiting, circulatory collapse, 
Table 1. Demographic Features, Clinical Features on Admission, Treatment, and Outcomes in Patients With Snakebites $(\mathrm{n}=151)$

\begin{tabular}{|c|c|}
\hline Clinical Features of Snakebite & Values $^{\mathrm{a}}$ \\
\hline Average age, mo & $119.6 \pm 37.8$ \\
\hline \multicolumn{2}{|l|}{ Gender } \\
\hline Male & $99(65.6)$ \\
\hline Female & $52(34.4)$ \\
\hline \multicolumn{2}{|l|}{ Area of occurrence } \\
\hline Rural area & $99(65.6)$ \\
\hline Urban area & $52(34.4)$ \\
\hline \multicolumn{2}{|l|}{ Location of bite site } \\
\hline Right forearm & $93(61.6)$ \\
\hline Right foot & $27(17.9)$ \\
\hline Right hand & $9(6.0)$ \\
\hline Left foot & $9(6.0)$ \\
\hline Left hand & $5(3.3)$ \\
\hline Left hip & $4(2.6)$ \\
\hline Left shoulder & $2(1.3)$ \\
\hline Left leg & $1(0.7)$ \\
\hline Right leg & $1(0.7)$ \\
\hline Duration of hospitalization, $d$ & $6(1-26)$ \\
\hline \multicolumn{2}{|l|}{ Severity of Envenomation } \\
\hline Mild & $32(21.2)$ \\
\hline Moderate & $73(48.3)$ \\
\hline Severe & $46(30.5)$ \\
\hline \multicolumn{2}{|l|}{ Symptoms and clinical findings } \\
\hline Edema & $143(94.7)$ \\
\hline Ecchymosis & $112(74.2)$ \\
\hline Necrosis & $45(29.8)$ \\
\hline Tachycardia & $34(22.5)$ \\
\hline Vesicle or bulla & $32(21.2)$ \\
\hline Dyspnea & $32(21.2)$ \\
\hline Hypotension & $29(19.2)$ \\
\hline Electrocardiogram changes & $11(7.3)$ \\
\hline \multicolumn{2}{|l|}{ Treatment } \\
\hline Antivenom dose, median & $1(1-5)$ \\
\hline Plaster splints & $48(31.8)$ \\
\hline Prophylactic antibiotic & $145(96.0)$ \\
\hline \multicolumn{2}{|l|}{ Clinical outcomes } \\
\hline Non-complicated recovery & $108(71.5)$ \\
\hline Complication & $43(28.5)$ \\
\hline Mortality & - \\
\hline
\end{tabular}

${ }^{a}$ Values are expressed as mean \pm standard deviation, median range or №. (\%)

jaundice, convulsion, and coma may develop $(4,8)$. Tekin et al. monitored 123 pediatric patients with snakebite and found that the most common findings were edema, ecchymosis, and vesicular lesions (3). In the present study, the most common findings were edema, ecchymosis, necrosis, and tachycardia.

Snakebites are mostly seen in the lower extremities. Snakebites on the head and on the body cause two to three times greater threat to life than those in the extremities (2,
9). Kshirsagar et al. reported that the most common locations of the bites were the right forearm and foot (10). In our study, the most common locations of snakebites were also the right forearm and foot. This finding may be related to the more human activities for agriculture in rural areas.

The clinical severity of the reaction to snakebite depends on its location, depth, amount of venom injected, species and size of the snake involved, age and size of the victim, and victim's sensitivity to the venom $(5,8,11)$. 
Table 2. Demographic Features and Laboratory Findings of Snakebite Severity Groups

\begin{tabular}{|c|c|c|c|c|}
\hline Demographic Features & $\operatorname{Mild}(\mathbf{n}=32)$ & Moderate $(n=73)$ & Severe $(n=46)$ & PValue \\
\hline Age, mo & $131(36-190)$ & $120(25-180)$ & $132(25-190)$ & 0.725 \\
\hline Gender & & & & 0.695 \\
\hline Female & $11(34.3)$ & $23(31.5)$ & $18(39.1)$ & \\
\hline Male & $21(65.7)$ & $50(68.5)$ & $28(60.9)$ & \\
\hline Area of occurrence & & & & 0.001 \\
\hline Rural area & $21(65.7)$ & $36(49.3)$ & $42(91.3)$ & \\
\hline Urban area & $11(34.3)$ & $37(50.7)$ & $4(8.7)$ & \\
\hline Duration of hospitalization, $d$ & $4(1-13)$ & $5(1-20)$ & $9(1-26)$ & $<0.001$ \\
\hline \multicolumn{5}{|c|}{ Laboratory findings at admission } \\
\hline WBC, K/uL & $11.1 \pm 4.6$ & $15.0 \pm 6.5$ & $16.7 \pm 7.8$ & 0.002 \\
\hline Hemoglobin, g/dL & $12.8 \pm 1.2$ & $13.4 \pm 1.5$ & $13.1 \pm 2.5$ & 0.163 \\
\hline Platelet count, K/uL & $291 \pm 82$ & $296 \pm 101$ & $265 \pm 106$ & 0.154 \\
\hline Urea, mg/dL & $26.4 \pm 9.8$ & $27.4 \pm 8.9$ & $29.1 \pm 11.7$ & 0.812 \\
\hline Creatine, $\mathrm{mg} / \mathrm{dL}$ & $0.5 \pm 0.1$ & $0.5 \pm 0.2$ & $0.5 \pm 0.2$ & 0.302 \\
\hline Calcium, mg/dL & $9.3 \pm 0.6$ & $9.4 \pm 1.0$ & $8.8 \pm 0.8$ & 0.005 \\
\hline AST/ALT ratio, U/L & $1.5 \pm 0.5$ & $1.8 \pm 0.6$ & $2.1 \pm 0.8$ & 0.010 \\
\hline Total Protein, g/dL & $7.0 \pm 0.7$ & $6.7 \pm 0.8$ & $6.2 \pm 1.0$ & 0.001 \\
\hline Albumin, $\mathrm{g} / \mathrm{dL}$ & $3.9 \pm 0.4$ & $3.8 \pm 0.3$ & $3.3 \pm 0.6$ & $<0.001$ \\
\hline $\mathrm{CK}, \mathrm{U} / \mathrm{L}$ & $169 \pm 136$ & $243 \pm 204$ & $535 \pm 598$ & 0.001 \\
\hline PT, sn & $13.6 \pm 2.5$ & $14.0 \pm 3.3$ & $13.1 \pm 3.5$ & 0.516 \\
\hline
\end{tabular}

Abbreviations: AST/ALT ratio, aspartate aminotransferase to alanine aminotransferase ratio; CK, creatine kinase; PT, prothrombin time; SD, standard deviation; WBC, white blood cell.

Table 3. Comparison of Laboratory Findings of Patients According to 1 Day, 5 Days, and 10 Days ${ }^{\mathrm{a}}$

\begin{tabular}{lccc}
\hline Parameters & 1 Day & 5 Days & 10 Days \\
\hline WBC, K/UL & $15.7 \pm 5.4$ & $9.9 \pm 3.5$ & $10.3 \pm 6.7$ \\
Platelet count, K/UL & $258 \pm 113$ & $193 \pm 96$ & $257 \pm 108$ \\
AST/ALT ratio, U/L & $1.8 \pm 0.7$ & $1.6 \pm 0.7$ & - \\
\hline
\end{tabular}

Abbreviations: AST/ALT ratio, aspartate aminotransferase to alanine aminotransferase ratio; SD, standard deviation; WBC, white blood cell.

${ }^{\mathrm{a}}$ Values are expressed as mean $\pm \mathrm{SD}$

Feitosa et al. found that age $\leq 15$ years, delayed medical treatment $>6$ hours, and rural workers bitten by snakes were independently associated with the risk of developing severity and mortality (12). Ogunfowokan et al. found that a delay in antivenom administration was also a risk factor for the severity of snakebites (13). In the present study, most of the patients had moderate and then severe clinical presentation due to delays in reaching the central hospital from their rural areas or hospitals. This result is considered to be due to the fact that the patients in the rural areas know what to do. They immediately seek treatment for snakebite, but some local hospitals fail to have sufficient equipment and drugs such as antivenom in store. Currently, no adequate data on medical treatment are available for our study.

After snakebite, complications such as cellulitis, disseminated intravascular coagulation, pulmonary edema, acute renal failure, compartment syndrome, and death may occur. Compartment syndrome is a rare complication resulting in the loss of function due to ischemia and extremity amputation if untreated $(2,9)$. Halesha et al. reported that respiratory insufficiency and renal failure were 
the more frequent complications of snakebites (14). Therefore, researchers believe that the administration of medical treatments such as elevation and antibiotics, whenever necessary, should be held off until the clinical findings are completely settled, and that fasciotomy should be performed when clinically suspected. Abbey et al. monitored 90 patients with snakebites and found 31 patients had complications and 20 patients required surgical intervention (15). In the present study, a plaster splint was applied to $31.8 \%$ of the patients, and fasciotomy was performed in all cases that developed compartment syndrome. In our study, $28.5 \%$ of the children developed compartment syndrome, and this rate is higher than that in the general literature. Researchers believe that this finding is due to the fact that compartment syndrome mostly occurs in moderate and severe cases, and that most of these cases had delayed admittance to the hospital $(2,9)$.

Baseline laboratory tests should include a complete blood count with platelet count, electrolytes, blood urea nitrogen, and prothrombin time (16). Campbell et al. reported that leukocytosis recovered on the first day of the follow-up, but thrombocyte count and hemoglobin amount were reduced (6). In the current study, leukocytosis and neutrophilia were significantly higher in the severe snakebite group than in other groups. However, in terms of hemoglobin, platelet count, urea, creatine, and prothrombin time, no statistically significant difference was observed among the subgroups of snakebite severity. Similar to previous studies, WBC and hemoglobin amounts decreased on subsequent days among snakebite patients in our study.

Snake venom that causes rhabdomyolysis may result in myoglobinuria, hyperphosphatemia, hyperpotassemia, hypoproteinemia, hypoalbuminemia, hypocalcemia, and elevated serum AST and creatinine phosphokinase levels $(1,9)$. In the present study, elevated AST, ALT, creatinine phosphokinase, hypoproteinemia, hypoalbuminemia, and hypocalcemia were observed more frequently in the severe group than in others.

Several authors have recommended abandoning prophylactic antibiotic treatment because of the risk of wound infection if viper envenomation is low. The venom effects of blistering and swelling are commonly mistaken for bacterial infection $(5,11,17)$. Alkaabi et al. suggested that increased infection parameters should be evaluated for starting antibiotics in patients with fever in the presence of necrosis or abscess (7). Tekin et al. reported that all of the pediatric patients with snakebite received prophylactic treatment with antibiotics, whereas 62 (37.1\%) adult patients with snakebite received antimicrobial treatments because of soft tissue infection (3). In our study, $96 \%$ of the patients received prophylactic antibiotic treatment. How- ever, in our cases, the decision to use such a high quantity of antibiotics might have been based on their symptoms and findings. For this reason, we believe that some of the patients might have received antibiotics unnecessarily. Therefore, we propose that randomized controlled trials should be conducted to determine the efficacy of prophylactic antibiotic treatment in snakebites.

The use of heparin, steroids, antibiotics, and routine vaccination against tetanus were frequent in snakebite cases in the past $(8,16)$. Currently, the primary treatment consists of antivenom, bleeding, pain management, and surgical interventions if necessary. Our records did not include detailed data for the use of tetanus toxoid. The administration and dose of antivenom should be determined on the basis of disease severity, location of the bite, and size of the patient. Children receive a higher dose of venom because of their relatively smaller size $(7,18)$. Campbell et al. monitored 114 pediatric patients with snakebite and used antivenom only in $6 \%$ of cases, and no mortality was found in their study (6). Abbey et al. reported that 88 of 90 patients received a median of 10 vials of antivenom that was well tolerated and that none of the patients died (15). In the present study, patients received one dose of antivenom on average, but those who had moderate or severe presentation received five doses. Furthermore, no side effects of the antivenom injection and no fatalities were observed in our study. Researchers still recommend administering antivenom to patients admitted due to snakebites and believe that multi-center, randomized, controlled trials are required in the non-administration of antivenom.

Our study has several limitations: 1) it is a retrospective study with a relatively small sample size. 2) We have no data on laboratory parameters on the following days, and thus we could not compare more parameters and conduct statistical analysis. 3) A large amount of prophylactic antibiotic treatment could have affected some laboratory parameters on the following days.

In conclusion, snakebites are a life-threatening condition that can lead to prolonged hospitalization because of the impairment of laboratory parameters, soft tissue infection, compartment syndrome, and disseminated intravascular coagulopathy. Earlier treatment with antivenom and closed monitoring of clinical status and laboratory parameters such as WBC, AST, and ALT levels have decreased prolonged hospitalization, morbidity, and mortality in patients with snakebite.

\section{Acknowledgments}

We acknowledge Prof. Aydın Ece for the language editing he performed on this manuscript. 


\section{Footnote}

Authors' Contribution: Fesih Aktar developed the study concepts and design. Ilyas Yolbas and Safak Aktar collected the data. Fesih Aktar and Recep Tekin analyzed and interpreted the data. Fesih Aktar and Safak Aktar wrote the manuscript. Fesih Aktar and Recep Tekin revised and edited the manuscript. All authors read and approved the final manuscript.

\section{References}

1. Chippaux JP. Epidemiology of snakebites in Europe: a systematic review of the literature. Toxicon. 2012;59(1):86-99. doi: 10.1016/j.toxicon.2011.10.008. [PubMed: 22056768].

2. Chew KS, Khor HW, Ahmad R, Rahman NH. A five-year retrospective review of snakebite patients admitted to a tertiary university hospital in Malaysia. Int J Emerg Med. 2011;4:41. doi: 10.1186/1865-1380-4-41. [PubMed: 21752254].

3. Tekin R, Sula B, Cakir G, Aktar F, Deveci O, Yolbas I, et al. Comparison of snakebite cases in children and adults. Eur Rev Med Pharmacol Sci. 2015;19(14):2711-6. [PubMed: 26221904].

4. Otero-Patino R. Epidemiological, clinical and therapeutic aspects of Bothrops asper bites. Toxicon. 2009;54(7):998-1011. doi: 10.1016/j.toxicon.2009.07.001. [PubMed:19591857].

5. Al B, Orak M, Aldemir M, Guloglu C. Snakebites in adults from the Diyarbakir region in southeast Turkey. Ulus Travma Acil Cerrahi Derg. 2010;16(3):210-4. [PubMed: 20517744].

6. Campbell BT, Corsi JM, Boneti C, Jackson RJ, Smith SD, Kokoska ER. Pediatric snakebites: lessons learned from 114 cases. J Pediatr Surg. 2008;43(7):1338-41. doi: 10.1016/j.jpedsurg.2007.11.011. [PubMed: 18639692].

7. Alkaabi JM, Al Neyadi M, Al Darei F, Al Mazrooei M, Al Yazedi J, Abdulle AM. Terrestrial snakebites in the South East of the Arabian Peninsula: patient characteristics, clinical presentations, and management. PLoS One. 2011;6(9):e24637. doi: 10.1371/journal.pone.0024637. [PubMed: 21931788].
8. Monteiro FN, Kanchan T, Bhagavath P, Kumar GP, Menezes RG, Yoganarasimha K. Clinico-epidemiological features of viper bite envenomation: a study from Manipal, South India. Singapore Med J 2012;53(3):203-7. [PubMed: 22434296].

9. Ahmed SM, Nadeem A, Islam MS, Agarwal S, Singh L. Retrospective analysis of snake victims in Northern India admitted in a tertiary level institute. J Anaesthesiol Clin Pharmacol. 2012;28(1):45-50. doi: 10.4103/0970-9185.92434. [PubMed: 22345945].

10. Kshirsagar VY, Ahmed M, Colaco SM. Clinical profile of snake bite in children in rural India. Iran J Pediatr. 2013;23(6):632-6. [PubMed: 24910739].

11. Schmidt JM. Antivenom therapy for snakebites in children: is there evidence?. Curr Opin Pediatr. 2005;17(2):234-8. [PubMed:15800419].

12. Feitosa EL, Sampaio VS, Salinas JL, Queiroz AM, da Silva IM, Gomes AA, et al. Older Age and Time to Medical Assistance Are Associated with Severity and Mortality of Snakebites in the Brazilian Amazon: A Case-Control Study. PLoS One. 2015;10(7):e0132237. doi: 10.1371/journal.pone.0132237. [PubMed: 26168155].

13. Ogunfowokan O, Jacob DA, Livinus OL. Relationship between bite-tohospital time and morbidity in victims of carpet viper bite in NorthCentral Nigeria. West Afr J Med. 2011;30(5):348-53. [PubMed: 22752823]

14. Halesha BR, Harshavadhan L, Lokesh AJ. A study on the clinicoepidemiological profile and the outcome of snake bite victims in a tertiary care centre in southern India. J Clin Diagn Res. 2013;7(1):122-6. doi: 10.7860/JCDR/2012/4842.2685. [PubMed: 23450135].

15. Abbey JM, Jaffar NA, Abugrara HL, Nazim M, Smalligan RD, Khasawneh FA. Epidemiological characteristics, hospital course and outcome of snakebite victims in West Texas. Hosp Pract (1995). 2015;43(4):217-20 doi: 10.1080/21548331.2015.1071637. [PubMed: 26189356].

16. Ouyang C, Teng CM, Huang TF. Characterization of snake venom components acting on blood coagulation and platelet function. Toxicon. 1992;30(9):945-66. [PubMed: 1440652].

17. Garg A, Sujatha S, Garg J, Acharya NS, Chandra Parija S. Wound in fections secondary to snakebite. J Infect Dev Ctries. 2009;3(3):221-3. [PubMed: 19759478].

18. Spiller HA, Bosse GM. Prospective study of morbidity associated with snakebite envenomation. J Toxicol Clin Toxicol. 2003;41(2):125-30. [PubMed: 12733849]. 